[Med. Entomol. Zool. Vol. 60 No. 1 p. 23-31 2009]

\title{
Survey of tick fauna possessing the ability to act as vectors of rickettsiosis in Toyama Prefecture, Japan
}

\author{
Takeo Yamauchi ${ }^{1)}$, Mayumi Obara ${ }^{1)}$, Mamoru Watanabe ${ }^{1)}{ }^{2)}$, Shuji Ando ${ }^{3)}$, \\ Mitsuhiro Ishikura ${ }^{4)}$, Yasuhiro Shinagaw ${ }^{1)}$, Sumiyo Hasegawa ${ }^{1)}$, \\ Kazuya Nakamura ${ }^{1)}$, Masae Iwai $^{1)}$, Takeshi Kurata ${ }^{1)}$ \\ and Takenori TAKIZAWA ${ }^{1)}$ \\ 1) Toyama Institute of Health, Nakataikoyama 17-1, Imizu, Toyama, 939-0363 Japan \\ 2) Department of Medical Entomology, National Institute of Infectious Diseases, \\ Toyama 1-23-1, Shinjuku-ku, Tokyo, 162-8640 Japan \\ 3) Department of Virology I, National Institute of Infectious Diseases, Toyama 1-23-1, \\ Shinjuku-ku, Tokyo, 162-8640 Japan \\ 4) Kashima-cho, Toyama, 930-0086 Japan
}

(Received: 1 October 2008; Accepted: 5 January 2009)

\begin{abstract}
During 1991-2007 a total of 3,562 ixodid ticks were collected by flagging at altitudes from 20 to $1,470 \mathrm{~m}$ in Toyama Prefecture. Two genera and nine species were identified as follows: Haemaphysalis flava, H. japonica, H. kitaokai, $H$. longicornis, H. megaspinosa, Ixodes monospinosus, I. nipponensis, I. ovatus, and I. persulcatus. Ixodes ovatus was the most dominant species at elevations of $400 \mathrm{~m}$ and above, but was also distributed at the low altitudes. Haemaphysalis flava was predominant below $401 \mathrm{~m}$ above sea level. Haemaphysalis kitaokai, H. megaspinosa, and I. monospinosus were newly recorded in Toyama Prefecture. Rickettsial DNA detected from I. monospinosus was closely related to Rickettsia helvetica, indicating a potential threat of spotted fever group rickettsial infection in Toyama Prefecture.
\end{abstract}

Key words: Honshu, Haemaphysalis, Ixodes, Ixodidae, spotted fever group Rickettsia, vertical distribution

\section{INTRODUCTION}

Ticks transmit a greater variety of pathogenic microorganisms than any other arthropod vector groups, and are one of the most important vectors carrying diseases to humans, livestock, and companion animals (Jongejan and Uilenberg, 2004). In Japan, patients of tick-borne diseases including Japanese spotted fever (JSF), Lyme disease, tularemia, and tick-borne encephalitis have been reported (Takada, 2007). Recently, fatal cases of JSF caused by Rickettsia japonica were reported in Japan (Nomura et al., 2007), and concerns for tick-borne diseases are increasing. Because endemic areas of spotted fever group (SFG) rickettsioses are rather latent, careful monitoring of SFG rickettsioses as an emerging infectious disease is required even in Toyama Prefecture where JSF patients have not yet been identified.

The occurrence of tick-borne disease is essentially correlated with the distribution of vector ticks. Therefore, it is important to survey tick fauna and detect pathogenic microorganisms in ticks. Although eight tick species have so far been recorded in Toyama Prefecture: Amblyomma testudinarium, Haemaphysalis flava, H. japonica, H. longicornis, Ixodes acutitarsus, I. nipponensis, I. ovatus, I. persulcatus (Ishikura et al., 1994, 2003; Kamimura and Kondo, 1977; Kishida, 


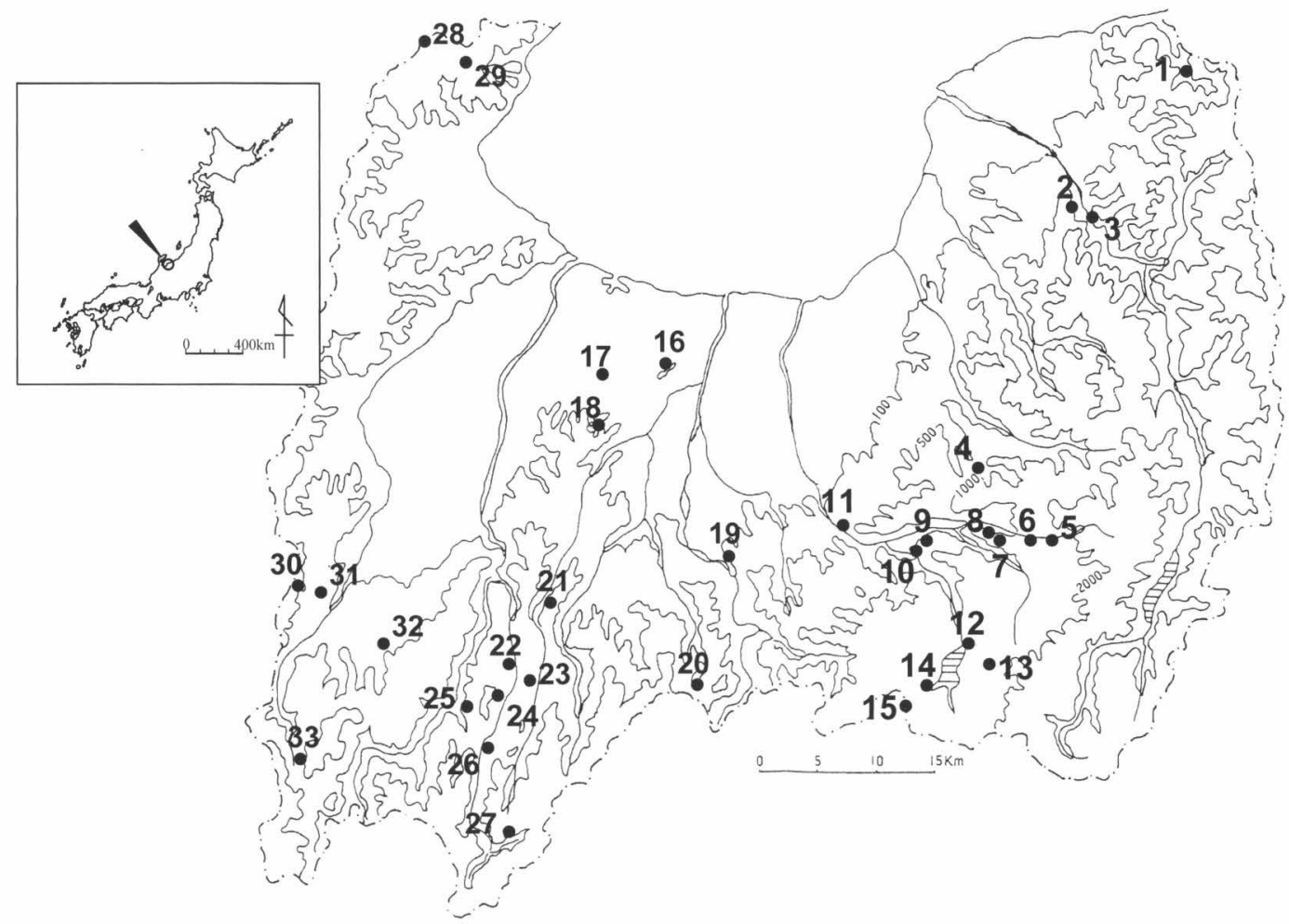

Fig. 1. Map showing survey sites in Toyama Prefecture.

Table 1. A list of collection sites and altitudes.

\begin{tabular}{rlcclc}
\hline \hline No. & \multicolumn{1}{c}{ Site } & $\begin{array}{c}\text { Altitude } \\
(\mathrm{m} \text { a.s.1.) }\end{array}$ & No. & \multicolumn{1}{c}{ Site } & $\begin{array}{c}\text { Altitude } \\
\text { (m a.s.1.) }\end{array}$ \\
\hline 1 & Daira-takifuchi & $240-300$ & 18 & Furudô-no-mori & $110-140$ \\
2 & Sôgatake-tozanguchi & $520-618$ & 19 & Sarukurayama & 345 \\
3 & Sôgatake-guchi & 850 & 20 & Shirakimine & 750 \\
4 & Banbajima & 900 & 21 & Tochioretôge & $520-600$ \\
5 & Daikandai & 1,470 & 22 & Kitajima & $445-500$ \\
6 & Tateyama-bunadaira & 1,200 & 23 & Togamura-kamimomose & 740 \\
7 & Bunasaka & 1,100 & 24 & Yamanokami & 840 \\
8 & Tateyama-bijodaira & $970-1,000$ & 25 & Tamukai & 350 \\
9 & Hanakiri & $600-700$ & 26 & Oku-daikanba & 950 \\
10 & Kamegai-akasaka & $600-610$ & 27 & Togamura-mizunashi & $900-1,000$ \\
11 & Tongariyama & 300 & 28 & Arayamatôge & $350-386$ \\
12 & Arimine-inonedani & 1,200 & 29 & Kakuma & $150-200$ \\
13 & Arimine-oritate & 1,400 & 30 & Iôzen & $780-800$ \\
14 & Arimine-tôgedani & 1,200 & 31 & Iôzen-guchi & $250-280$ \\
15 & Arimine-ôtawa & 1,290 & 32 & Ogaya & 250 \\
16 & Jyôyama & 100 & 33 & Bunaotôge & $980-990$ \\
17 & Taikôyama & 20 & & & \\
\hline
\end{tabular}

1930; Kondo et al., 1976; Shimada et al., 2003), there is not enough information on tick distributions in the prefecture. As for the rickettsial genes, several genotypes were detected in Toyama Prefecture until 2000 (Ishikura et al., 1994, 2003). 
In the present study, we collected and classified ixodid ticks in Toyama Prefecture and identified rickettsial genes in the ticks by polymerase chain reaction (PCR). In this way, we tried to clarify the distribution of ticks as vectors of spotted fever group rickettsiae (SFGR) and assess the risk of SFGR infection from ticks.

\section{Materials ANd Methods}

\section{Collection of ixodid ticks}

Ixodid ticks were collected by flagging at 33 sites (Fig. 1, Table 1) in Toyama Prefecture during 1991-2007. The survey sites ranged from 20 to $1,470 \mathrm{~m}$ above sea level (a. s. 1.). Of these, three sites (No. 1618) were located near residential areas and the remaining sites in mountainous areas. Field surveys by flagging were carried out 104 times. All of the adults and some of the nymphs attached to the white flannel flags were collected. Live ticks were identified by a microscope based on Yamaguti et al. (1971), Takada (1990), and Fujita and Takada (2007). After identification, some specimens were preserved under refrigeration or in $70 \%$ ethanol until PCR analysis.

\section{Detection of SFGR DNA}

From the ticks collected during 2006 and 2007, 184 adults and 59 nymphs (24 adults in 2006, 160 adults and 59 nymphs in 2007) were used for PCR analysis. The nymphs were separated into 16 groups containing five or less individuals. These samples were homogenized in PBS (-) and DNA was extracted with a QIAamp DNA Mini Kit (QIAGEN) according to the manufacturer's procedures. To amplify the 17-kDa outer membrane antigen gene, PCR was carried out with puRe Taq Ready-To-Go PCR Beads (GE Healthcare) using primers R1 and R2 for genus Rickettsia and primers $\operatorname{Rj} 5$ and $\operatorname{Rj} 10$ for $R$. japonica that amplify 537-540 bp and 357 bp, respectively, as described by Furuya et al. (1995). The mixture containing $2.5 \mu l$ of DNA was incubated at $95^{\circ} \mathrm{C}$ for $2 \mathrm{~min}$ and 35 cycles at $94^{\circ} \mathrm{C}$ for $45 \mathrm{sec}, 52^{\circ} \mathrm{C}$ for $30 \mathrm{sec}$ and $72^{\circ} \mathrm{C}$ for $45 \mathrm{sec}$.

After purification of the amplicons, the sequences were determined with the BigDye Terminator v3.1 Cycle sequencing Kit and ABI 3130 sequencer (Applied Biosystems). The sequences of the $17-\mathrm{kDa}$ genes were aligned using Clustal W (version 1.83). A phylogenetic tree was constructed by the neighbor-joining (NJ) method.

\section{RESUlTS}

\section{Collection of ixodid ticks}

A total of 3,562 ixodid ticks was collected. They were morphologically identified as two genera and nine species (Table 2). Ixodes ovatus was the most abundant (49.6\%), followed by H. flava (34.1\%), I. persulcatus (9.5\%), H. japonica (4.5\%), and $H$. longicornis (1.9\%). In contrast, four other species were captured in small numbers at limited sites: $H$. kitaokai was captured only at site No. $4 ; H$. megaspinosa only at site No. 18; I. monospinosus only at sites No. 2 and 3; I. nipponensis only at sites No. 16 and 18 (Table 1, Fig. 1). At the sites near residential areas (No. 16-18), the following five species: $H$. flava, $H$. longicornis, H. megaspinosa, I. nipponensis, I. ovatus were collected. Haemaphysalis kitaokai, H. megaspinosa, and I. monospinosus were newly recorded from Toyama Prefecture.

Figure 2 shows the species constructions of adult ticks at different altitudes. Haemaphysalis flava, H. japonica, I. ovatus, and $I$. persulcatus were captured at all altitudes, but species constructions of them vary depending on the altitude. Ixodes ovatus was the most dominant species at elevations from $400 \mathrm{~m}$ and above, but was also distributed at low altitudes in the relative high abundance. Haemaphysalis flava was predominant below $401 \mathrm{~m}$, diminished at higher altitudes and very few seen above $1,200 \mathrm{~m}$. The abundance of $I$. persulcatus increased at higher altitudes, and was very low below $401 \mathrm{~m}$. 
Table 2. Number of individuals of ixodid ticks collected by the flagging method at 33 sites in Toyama Prefecture.

\begin{tabular}{|c|c|c|c|c|c|c|c|c|c|c|c|c|c|c|c|c|c|c|c|c|c|c|c|c|c|c|c|c|c|c|c|c|c|c|c|c|}
\hline \multirow{2}{*}{ Tick } & & \multicolumn{34}{|c|}{ Collection site } & \multirow{2}{*}{ Total } \\
\hline & & 1 & 2 & 3 & 4 & 5 & 6 & 7 & 8 & 9 & 10 & 11 & 12 & 13 & 14 & 15 & 16 & 17 & 18 & 19 & 20 & 21 & 22 & & 232 & 24 & 25 & 26 & 27 & 28 & 29 & 30 & 31 & 32 & 33 & \\
\hline \multirow{3}{*}{ Haemaphysalis flava } & 우 & 0 & 0 & 0 & 0 & 0 & 0 & 0 & 8 & 0 & 2 & 0 & 0 & 1 & 0 & 0 & 0 & 0 & 487 & 1 & 0 & 1 & 0 & 0 & 0 & 0 & 0 & 0 & 0 & 8 & $8 \quad 5$ & 5 & 2 & 5 & 1 & 526 \\
\hline & $\sigma^{7}$ & 1 & 0 & 0 & 0 & 0 & 0 & 0 & 3 & 0 & 2 & 0 & 0 & 1 & 0 & 0 & 0 & 0 & 368 & 0 & 0 & 0 & 0 & 0 & 0 & 0 & 0 & 0 & $0 \quad 0$ & 6 & $6 \quad 3$ & 4 & 1 & 0 & 0 & 389 \\
\hline & Nymph & 0 & 5 & 0 & 0 & 0 & 0 & 0 & 20 & 10 & 5 & 0 & 0 & 2 & 0 & 0 & 0 & 20 & 143 & 0 & 0 & 0 & 0 & 0 & 0 & 1 & 1 & 0 & 1 & 156 & $6 \quad 5$ & 24 & 0 & 7 & 0 & 300 \\
\hline \multirow{3}{*}{ H. japonica } & 우 & 2 & 2 & 0 & 3 & 3 & 0 & 1 & 8 & 0 & 1 & 1 & 0 & 11 & 0 & 0 & 0 & 0 & 0 & 0 & 0 & 0 & 0 & 0 & 0 & 1 & 0 & 0 & $0 \quad 0$ & 0 & $0 \quad 0$ & 2 & 0 & 0 & 0 & 35 \\
\hline & $\sigma^{7}$ & 3 & 3 & 0 & 2 & 0 & 0 & 0 & 10 & 1 & 0 & 0 & 0 & 8 & 0 & 0 & 0 & 0 & 0 & 0 & 0 & 0 & 0 & 0 & 0 & 0 & 0 & 0 & $0 \quad 1$ & 0 & $0 \quad 0$ & 0 & 0 & 0 & 0 & 28 \\
\hline & Nymph & 3 & 34 & 0 & 0 & 2 & 0 & 0 & 13 & 12 & 2 & 0 & 0 & 19 & 0 & 1 & 0 & 0 & 0 & 0 & 0 & 0 & 0 & 0 & 1 & 2 & 0 & 1 & 10 & 1 & 10 & 5 & 0 & 0 & 1 & 97 \\
\hline \multirow{3}{*}{ H. kitaokai } & 우 & 0 & 0 & 0 & 0 & 0 & 0 & 0 & 0 & 0 & 0 & 0 & 0 & 0 & 0 & 0 & 0 & 0 & 0 & 0 & 0 & 0 & 0 & 0 & 0 & 0 & 0 & 0 & $0 \quad 0$ & 0 & $0 \quad 0$ & 0 & 0 & 0 & 0 & 0 \\
\hline & $\sigma^{x}$ & 0 & 0 & 0 & 1 & 0 & 0 & 0 & 0 & 0 & 0 & 0 & 0 & 0 & 0 & 0 & 0 & 0 & 0 & 0 & 0 & 0 & 0 & 0 & 0 & 0 & 0 & 0 & $0 \quad 0$ & 0 & $0 \quad 0$ & 0 & 0 & 0 & 0 & 1 \\
\hline & Nymph & 0 & 0 & 0 & 0 & 0 & 0 & 0 & 0 & 0 & 0 & 0 & 0 & 0 & 0 & 0 & 0 & 0 & 0 & 0 & 0 & 0 & 0 & 0 & 0 & 0 & 0 & 0 & 0 & 0 & $\begin{array}{ll}0 & 0\end{array}$ & 0 & 0 & 0 & 0 & 0 \\
\hline \multirow{3}{*}{ H. longicornis } & 우 & 0 & 0 & 0 & 0 & 0 & 0 & 0 & 1 & 0 & 0 & 0 & 0 & 0 & 0 & 0 & 0 & 0 & 1 & 0 & 0 & 0 & 0 & 0 & 0 & 0 & 0 & 0 & 0 & 0 & $0 \quad 1$ & 0 & 0 & 0 & 0 & 3 \\
\hline & $0^{x}$ & 0 & 0 & 0 & 0 & 0 & 0 & 0 & 1 & 0 & 0 & 0 & 0 & 0 & 0 & 0 & 0 & 0 & 0 & 0 & 0 & 0 & 0 & 0 & 0 & 0 & 0 & 0 & 0 & 0 & $0 \quad 0$ & 0 & 0 & 0 & 0 & 1 \\
\hline & Nymph & 0 & 0 & 0 & 0 & 0 & 0 & 0 & 0 & 0 & 0 & 0 & 0 & 0 & 0 & 0 & 0 & 18 & 4 & 0 & 0 & 0 & 0 & 0 & 0 & 0 & 0 & 0 & 0 & 6 & $6 \quad 36$ & 0 & 0 & 0 & 0 & 64 \\
\hline \multirow{3}{*}{ H. megaspinosa } & 우 & 0 & 0 & 0 & 0 & 0 & 0 & 0 & 0 & 0 & 0 & 0 & 0 & 0 & 0 & 0 & 0 & 0 & 0 & 0 & 0 & 0 & 0 & 0 & 0 & 0 & 0 & 0 & 0 & 0 & $0 \quad 0$ & 0 & 0 & 0 & 0 & 0 \\
\hline & $9^{7}$ & 0 & 0 & 0 & 0 & 0 & 0 & 0 & 0 & 0 & 0 & 0 & 0 & 0 & 0 & 0 & 0 & 0 & 1 & 0 & 0 & 0 & 0 & 0 & 0 & 0 & 0 & 0 & 0 & 0 & 0 & 0 & 0 & 0 & 0 & 1 \\
\hline & Nymph & 0 & 0 & 0 & 0 & 0 & 0 & 0 & 0 & 0 & 0 & 0 & 0 & 0 & 0 & 0 & 0 & 0 & 0 & 0 & 0 & 0 & 0 & 0 & 0 & 0 & 0 & 0 & 0 & 0 & 0 & 0 & 0 & 0 & 0 & 0 \\
\hline \multirow{3}{*}{ Ixodes monospinosus } & 우 & 0 & 2 & 0 & 0 & 0 & 0 & 0 & 0 & 0 & 0 & 0 & 0 & 0 & 0 & 0 & 0 & 0 & 0 & 0 & 0 & 0 & 0 & 0 & 0 & 0 & 0 & 0 & 0 & 0 & 0 & 0 & 0 & 0 & 0 & 2 \\
\hline & $0^{7}$ & 0 & 2 & 3 & 0 & 0 & 0 & 0 & 0 & 0 & 0 & 0 & 0 & 0 & 0 & 0 & 0 & 0 & 0 & 0 & 0 & 0 & 0 & 0 & 0 & 0 & 0 & 0 & 0 & 0 & 0 & 0 & 0 & 0 & 0 & 5 \\
\hline & Nymph & 0 & 0 & 0 & 0 & 0 & 0 & 0 & 0 & 0 & 0 & 0 & 0 & 0 & 0 & 0 & 0 & 0 & 0 & 0 & 0 & 0 & 0 & 0 & 0 & 0 & 0 & 0 & 0 & 0 & 0 & 0 & 0 & 0 & 0 & 0 \\
\hline \multirow{3}{*}{ I. nipponensis } & 우 & 0 & 0 & 0 & 0 & 0 & 0 & 0 & 0 & 0 & 0 & 0 & 0 & 0 & 0 & 0 & 1 & 0 & 3 & 0 & 0 & 0 & 0 & 0 & 0 & 0 & 0 & 0 & 0 & 0 & 0 & 0 & 0 & 0 & 0 & 4 \\
\hline & 8 & 0 & 0 & 0 & 0 & 0 & 0 & 0 & 0 & 0 & 0 & 0 & 0 & 0 & 0 & 0 & 0 & 0 & 0 & 0 & 0 & 0 & 0 & 0 & 0 & 0 & 0 & 0 & 0 & 0 & 0 & 0 & 0 & 0 & 0 & 0 \\
\hline & Nymph & 0 & 0 & 0 & 0 & 0 & 0 & 0 & 0 & 0 & 0 & 0 & 0 & 0 & 0 & 0 & 0 & 0 & 0 & 0 & 0 & 0 & 0 & 0 & 0 & 0 & 0 & 0 & 0 & 0 & 0 & 0 & 0 & 0 & 0 & 0 \\
\hline \multirow{3}{*}{ I. ovatus } & 우 & 14 & 5 & 1 & 58 & 33 & 1 & 5 & 71 & 6 & 16 & 1 & 1 & 418 & 7 & 35 & 15 & 0 & 184 & 0 & 3 & 0 & 1 & 1 & 0 & 0 & 0 & 4 & $4 \quad 19$ & 4 & 3 & 54 & 0 & 0 & 4 & 963 \\
\hline & 8 & 18 & 5 & 1 & 41 & 22 & 2 & 2 & 77 & 4 & 13 & 3 & 0 & 298 & 3 & 32 & 8 & 0 & 155 & 0 & 1 & 0 & 3 & 3 & 1 & 4 & 0 & 1 & $1 \quad 14$ & 3 & 0 & 69 & 0 & 0 & 10 & 790 \\
\hline & Nymph & 0 & 0 & 0 & 6 & 0 & 0 & 0 & 5 & 0 & 0 & 0 & 0 & 0 & 0 & 0 & 2 & 0 & 0 & 0 & 0 & 0 & 0 & 0 & 0 & 0 & 0 & 0 & $0 \quad 0$ & 0 & 0 & 0 & 0 & 0 & 0 & 13 \\
\hline \multirow{3}{*}{ 1. persulcatus } & 우 & 1 & 0 & 0 & 7 & 13 & 0 & 4 & 10 & 0 & 0 & 0 & 0 & 91 & 1 & 19 & 0 & 0 & 0 & 0 & 0 & 0 & 0 & 0 & 0 & 0 & 0 & 2 & 7 & $\begin{array}{ll}7 & 0\end{array}$ & 0 & 2 & 0 & 0 & 1 & 158 \\
\hline & $\sigma^{7}$ & 1 & 0 & 0 & 6 & 10 & 0 & 2 & 8 & 0 & 0 & 0 & 0 & 94 & 3 & 22 & 0 & 0 & 0 & 0 & 1 & 0 & 0 & 0 & 0 & 0 & 0 & 3 & 8 & 80 & 0 & 0 & 0 & 0 & 4 & 162 \\
\hline & Nymph & 0 & 0 & 0 & 6 & 1 & 0 & 0 & 2 & 0 & 0 & 0 & 0 & 8 & 0 & 1 & 0 & 0 & 0 & 0 & 1 & 0 & 0 & 0 & 0 & 0 & 0 & 0 & 1 & 0 & 0 & 0 & 0 & 0 & 0 & 20 \\
\hline Total & & 43 & 58 & 51 & 30 & 84 & 3 & 142 & 237 & 33 & 41 & 5 & 1 & 951 & 14 & 110 & 26 & 38 & 1,346 & 1 & 6 & 1 & 1 & 4 & 2 & 8 & 1 & 11 & 151 & 184 & $4 \quad 53$ & 165 & 3 & 12 & 21 & 3,562 \\
\hline
\end{tabular}




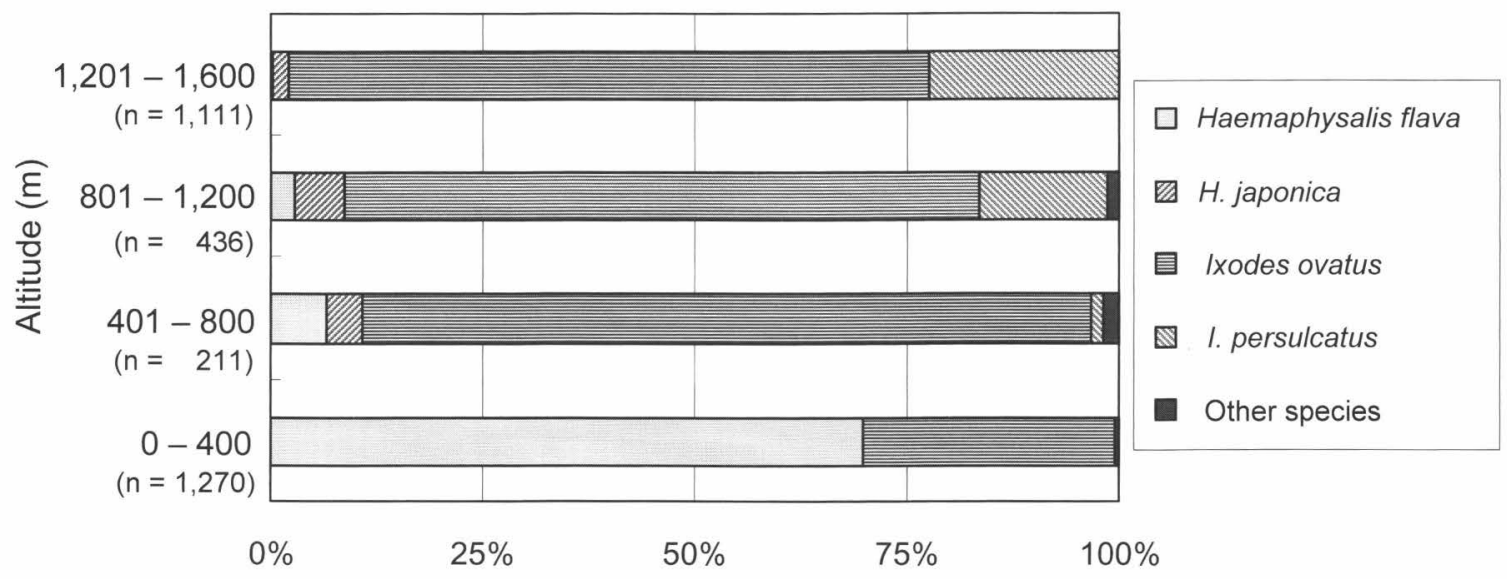

Fig. 2. Species constructions of adult ticks at different altitudes divided into four zones ranging from $0-400,401-800,801-1,200$, and 1,201-1,600 m.

Table 3. Prevalence of rickettsial 17-kDa genes detected from ticks by PCR.

\begin{tabular}{|c|c|c|c|c|}
\hline \multirow{3}{*}{ Tick species } & \multicolumn{4}{|c|}{ No. positive/tested } \\
\hline & \multicolumn{3}{|c|}{ Adult } & \multirow{2}{*}{ Nymph* } \\
\hline & 우 & 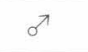 & Total $(\%)$ & \\
\hline Haemaphysalis flava & $3 / 85$ & $0 / 49$ & $3 / 134(2.2)$ & $2 / 12$ \\
\hline H. japonica & $0 / 4$ & $1 / 1$ & $1 / 5(20.0)$ & $0 / 2$ \\
\hline H. longicornis & $0 / 1$ & - & $0 / 1(0.0)$ & $0 / 2$ \\
\hline Ixodes monospinosus & $1 / 2$ & $1 / 2$ & $2 / 4(50.0)$ & - \\
\hline I. nipponensis & $0 / 1$ & - & $0 / 1(0.0)$ & - \\
\hline I. ovatus & $0 / 13$ & $0 / 7$ & $0 / 20(0.0)$ & - \\
\hline I. persulcatus & $0 / 6$ & $0 / 13$ & $0 / 19(0.0)$ & - \\
\hline Total & $4 / 112$ & $2 / 72$ & $6 / 184(3.3)$ & $2 / 16$ \\
\hline
\end{tabular}

* Shown by pool number.

Haemaphysalis japonica was mostly collected within the range of $801-1,200 \mathrm{~m}$, and very few occurred below $401 \mathrm{~m}$.

\section{Detection of SFGR DNA}

Rickettsial genes were detected from $H$. flava (3 females and 2 nymphal groups), $H$. japonica (1 male), and I. monospinosus (1 male and 1 female) (Table 3 ). The prevalences of rickettsia in adult $H$. flava, $H$. japonica and I. monospinosus were $2.2 \%$, $20.0 \%$ and $50.0 \%$, respectively. The phylogenetic tree of detected rickettsial $17 \mathrm{k}-\mathrm{Da}$ antigen genes is shown in Fig. 3. All rickettsial DNA samples were similar to the DNA already detected in Toyama
Prefecture (Ishikura et al., 2003). Four rickettsial DNA samples out of five detected from $H$. flava were closely related to Hf332. Rickettsial DNA No. T272 showed 99.0\% nucleotide sequence homology with Hf332. A rickettsial DNA sample detected from $H$. japonica was closely related to $\mathrm{Hj} 126$. Two rickettsial DNA samples detected from I. monospinosus were closely related to Ip382 and differed in three nucleotides $199.3 \%$ identical) from that of $R$. helvetica. The $R$. japonica gene was not detected in the present study. 


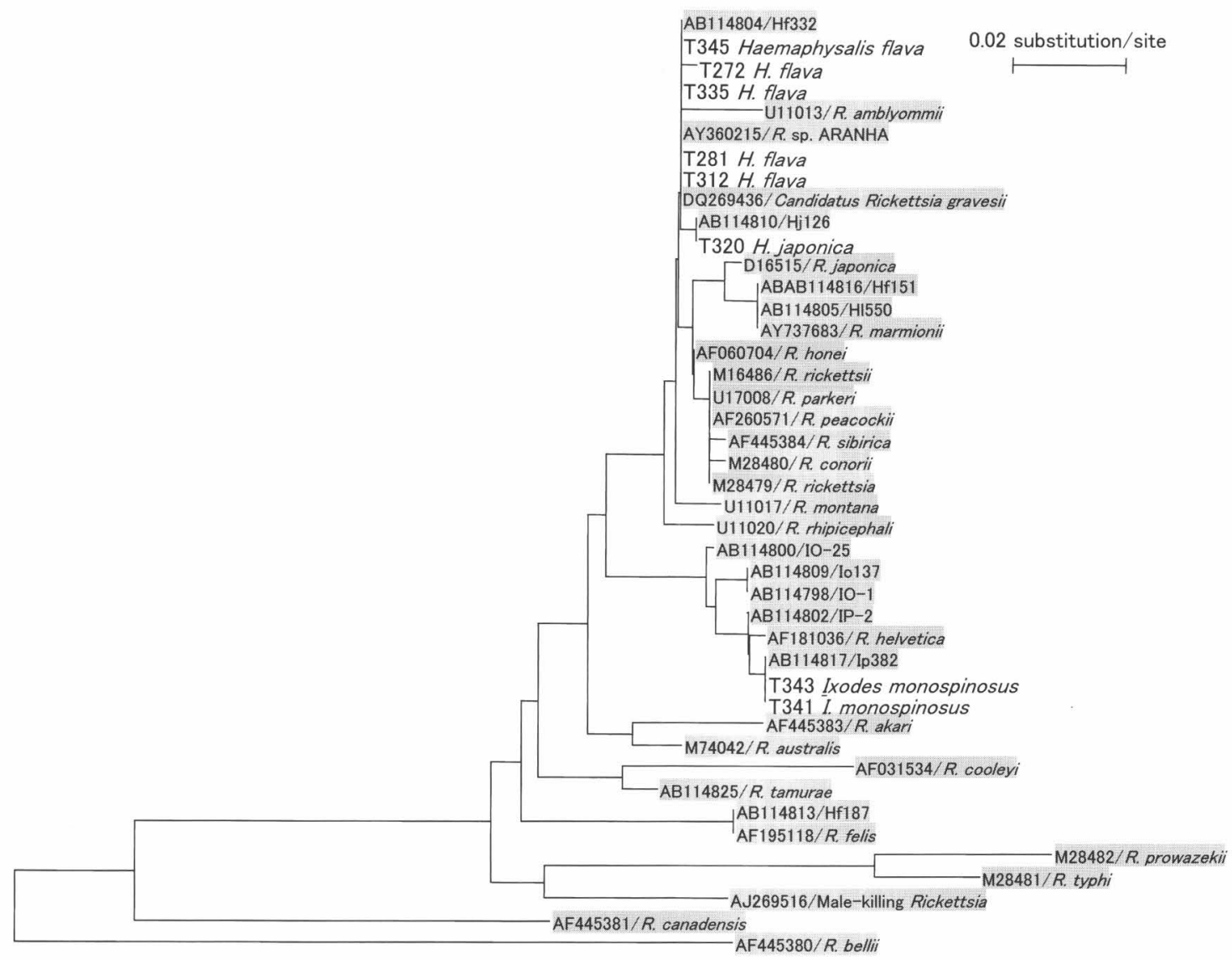

Fig. 3. Phylogenetic tree constructed based on the $17-\mathrm{kDa}$ gene sequence of the spotted fever group rickettsiae from ticks. Samples are shown by No. and species. Reference strains are shaded and shown as "accession No./strain".

\section{Discussion}

On the basis of the field surveys during 1991-2007, we recorded the tick fauna on vegetation below $1,470 \mathrm{~m}$ a.s.l. in Toyama Prefecture. Although nine tick species including three species newly recorded for the prefecture were collected, the following two species, $A$. testudinarium and $I$. acutitarsus, previously recorded in the prefecture were not found. Two species were recorded only from host animals in the prefecture: A. testudinarium was from human (Kamimura and Kondo, 1977; Kondo et al., 1976) and I. acutitarsus was from human and the Japanese serow Capricornis crispus (Kishida, 1930; Kondo et al., 1976). Further tick collections from host animals may clarify these tick fauna in Toyama Prefecture.

Haemaphysalis flava, a causative agent of JSF in the endemic area (Mahara, 1997), was the most dominant species at low altitudes in the study area and is similar to other studies in Honshu (Fujimoto and Yamaguti, 1990; Fujita et al., 1981) and Kyushu (Nakao and Takada, 1997). However, the vertical distribution of $H$. flava can not be explained by its wide host range including birds (Yamaguti et al., 1971) and its high tolerance to low temperature (Fujimoto, 1993). More detailed studies on the ecology of $H$. flava, including interspecific competition, are necessary to clarify the factors limiting its ver- 
tical distribution.

Although the vertical distribution of $H$. japonica has been poorly studied, known collecting areas of $H$. japonica were below 1,000 m (Fujita et al., 1981; Ishiguro et al., 1992). Haemaphysalis japonica at $1,470 \mathrm{~m}$ (site No. 5, see Table 1 and 2) is the highest altitude recorded for this species and suggests that $H$. japonica is tolerant to low temperatures.

Ixodes ovatus, was the most dominant species above $400 \mathrm{~m}$ in the present study, which is similarly to other studies in Honshu (Fujita et al., 1981; Fujimoto and Yamaguti, 1990; Ishiguro et al., 1992). The vertical distribution of $I$. ovatus appears to be because all developmental stages are less tolerant to high temperatures (Fujimoto, 1993).

Ixodes persulcatus, playing a significant role in the transmission of Lyme borreliosis spirochetes to humans in Japan (Miyamoto et al., 1991), are not distributed in the lower altitudes in the southern areas of central Honshu (Fujita et al., 1981; Fujimoto and Yamaguti, 1990; Ishiguro et al., 1992). The present findings are similar to these distributional patterns for $I$. persulcatus. A high tolerance to low temperatures in contrast to a low tolerance to high temperatures in I. persulcatus appears to be consistent with the vertical distribution of the species (Fujimoto, 1992, 1994).

High mountain ecosystems are considered sensitive to climate change. Recently, the vertical distribution limit of $I$. ricinus has obviously shifted to higher altitudes in the Krkonoše Mts., Czech Republic because of the changing climate (Materna et al., 2005; Danielová et al., 2008). In the present study, an obvious shift in vertical distribution of ticks was not observed because the distributional limit of ticks could not be precisely surveyed. However, shoot elongation of alpine dwarf pine Pinus pumila a principal component of vegetation in the alpine life zone has been affected by increasing summer temperatures during the last 25 years in Central Japan (Wada et al., 2005), so climate changes may affect the vertical distribution of ticks in Japan.

The rickettsial DNA detected from $I$. monospinosus was closely related to $R$. helvetica which is strongly considered to be the pathogen for SFGR infections in Fukui Prefecture (Noji et al., 2005; Takada et al., 2006; Ishiguro et al., 2008). Although I. monospinosus appears to be rare in Toyama Prefecture and was recorded only in the eastern mountain area (520$850 \mathrm{~m}$ a.s.1.), the prevalence of rickettsia in I. monospinosus is relatively high. Therefore, the present findings indicate a potential threat of SFGR infection from I. monospinosus in Toyama Prefecture.

\section{ACKNOWLEDGEMENTS}

We appreciate Mr. Eiji Horimoto of Toyama Institute of Health for his assistance in collecting ticks and Mrs. Miyuki Maekawa of Toyama Institute of Health for her assistance in detecting SFGR by the PCR technique. This study was supported in part by Grant-in-Aids for Scientific Research on Emerging and Reemerging Infectious Diseases from the Japanese Ministry of Health, Labour and Welfare.

\section{REFERENCES}

Danielová, V., Schwarzová, L., Materna, J., Daniel, M. Metelka, L., Holubová, J. and Kř́ǐz, B. 2008. Tickborne encephalitis virus expansion to higher altitudes correlated with climate warming. Int. J. Med. Microbiol., 298: 68-72.

Fujimoto, K. 1992. Comparative observations on oviposition and development of two ixodid ticks, Ixodes persulcatus Schulze and I. nipponensis Kitaoka and Saito, under different temperatures. Jpn. J. Sanit. Zool., 43: 105-112.

Fujimoto, K. 1993. Tolerances of Haemaphysalis longicornis, H. flava, and Ixodes ovatus (Acari: Ixodidae) to high and low temperatures in relation to distribution patterns of these ticks in the Chichibu Mountains. Jpn. J. Environ. Entomol. Zool., 5: 158165 . 
Fujimoto, K. 1994. Comparison of the cold hardiness of Ixodes nipponensis and I. persulcatus (Acari: Ixodidae) in relation to the distribution patterns of both species in the Chichibu Mountains. Jpn. J. Sanit. Zool., 45: 333-339.

Fujimoto, K. and Yamaguti, N. 1990. Ixodid ticks on vegetations and their seasonal occurrence at the upper montane to subalpine zones (ca. 600-1,800 m above sea level) of the Chichibu Mountains. Jpn. J. Sanit. Zool., 41: 341-346 (In Japanese with English summary).

Fujita, H. and Takada, N. 2007. Identification of immature ticks in Japan. In: Acari and Emerging/ Reemerging Disease (ed. Organization Committee of SADI), pp.53-68, Zenkoku Noson Kyoiku Kyokai Publishing Co. Ltd., Tokyo (In Japanese).

Fujita, H., Takahashi, M., Yamamoto, S., Saito, T. and Machida, K. 1981. Ixodid ticks (Acarina: Ixodidae) parasitic on mammals and birds in Saitama and Gunma Prefectures, central Japan. 1. Host-tick relationships, geographical and vertical distributions, and medical problems. Ann. Rep. Ohara Hosp., 24: 13-27 (In Japanese with English summary).

Furuya, Y., Katayama, T., Yoshida, Y. and Kaiho, I. 1995. Specific amplification of Rickettsia japonica DNA from clinical specimens by PCR. J. Clin. Microbiol., 33: 487-489.

Ishiguro, F., Iida, H., Hatano, M., Yano, Y. and Takada, N. 1992. Tick fauna and the prevalence of Lyme Borrelia in Fukui Prefecture. J. Acarol. Soc. Jpn., 1: 27-35 (In Japanese with English summary).

Ishiguro, F., Takada, N., Fujita, H., Noji, Y., Yano, Y. and Iwasaki, H. 2008. Survey of the vectorial competence of ticks in an endemic area of spotted fever group rickettsioses in Fukui Prefecture, Japan. Microbiol. Immunol., 52: 305-309.

Ishikura, M., Ando, S., Shinagawa, Y., Matsuura, K., Hasegawa, S., Nakayama, T., Fujita, H. and Watanabe, M. 2003. Phylogenetic analysis of spotted fever group rickettsiae based on gltA, 17-kDa, and rOmpA genes amplified by nested PCR from ticks in Japan. Microbiol. Immunol., 47: 823-832.

Ishikura, M., Watanabe, M., Shinagawa, Y., Matsuura, K. and Morita, O. 1994. Detection of spotted fever group rickettsia DNA in ticks by polymerase chain reaction technology. In: Acari-diseases Interface (ed. Organization Committee of SADI), pp. 137-140, Yuki Press Inc, Fukui (In Japanese with English abstract).

Jongejan, F. and Uilenberg, G. 2004. The global im- portance of ticks. Parasitology, 129: S3-S14.

Kamimura, K. and Kondo, K. 1977. Four cases of human infestation with three tick species Amblyomma testudinarium, Ixodes nipponensis and I. ovatus in Japan. Jpn. J. Sanit. Zool., 28: 249-250 (In Japanese).

Kishida, K. 1930. Notes on Japanese ticks of the genus Ixodes Latreille, 1795. Lansania, 2 (11): 1-5 (In Japanese).

Kondo, K., Yoshimura, H., Kamimura, K., Yonemura, D., Kawasaki, K., Fujinami, M. and Yamada, S. 1976. Human cases of infestation with ticks in Hokuriku District. Jpn. Med. J., 2725: 29-31 (In Japanese).

Mahara, F. 1997. Japanese spotted fever: report of 31 cases and review of the literature. Emerg. Infect. Dis., 3: 105-111.

Materna, J., Daniel, M. and Danielová, V. 2005. Altitudinal distribution limit of the tick Ixodes ricinus shifted considerably towards higher altitudes in central Europe: results of three years monitoring in the Krkonoše Mts. (Czech Republic). Cent. Eur. J. Public Health, 13: 24-28.

Miyamoto, K., Nakao, M. Sato, N. and Mori, M. 1991. Isolation of Lyme disease spirochetes from an ixodid tick in Hokkaido, Japan. Acta Trop., 49: 6568.

Nakao, M. and Takada, N. 1997. Survey of tick fauna in the Kyushu mainland, Japan. Med. Entomol. Zool., 48: 39-44 (In Japanese with English abstract). Noji, Y., Takada, N., Ishiguro, F., Fujino, S., Aoyama, T., Fujita, H., Yano, Y., Shiomi, S., Mitsuto, I., Takase, K., Haba, T. and Mabuchi, H. 2005. The first reported case of spotted fever in Fukui Prefecture, the northern part of central Japan. Jpn. J. Infect. Dis., 58: 112-114.

Nomura, T., Fujimoto, T., Ebisutani, C., Horiguchi, H. and Ando, S. 2007. The first fatal case of Japanese spotted fever confirmed by serological and microbiological tests in Awaji Island, Japan. Jpn. J. Infect. Dis., 60: 241-243.

Shimada, Y., Beppu, T., Inokuma, H., Okuda, M. and Onishi, T. 2003. Ixodid tick species recovered from domestic dogs in Japan. Med. Vet. Entomol., 17: 3845.

Takada, N. 1990. A Pictorial Review of Medical Acarology in Japan. 222 pp., Kinpodo, Kyoto (In Japanese).

Takada, N. 2007. Medical acarology in Japan vector outbreak-. In: Acari and Emerging/ 
Reemerging Disease (ed. Organization Committee of SADI), pp.39-42, Zenkoku Noson Kyoiku Kyokai Publishing Co. Ltd., Tokyo (In Japanese).

Takada, N., Ishiguro, F. and Fujita, H. 2006. The first case of spotted fever in Fukui Prefecture, suggesting serologically as $R$. helvetica infection. IASR, 27: 40-41.

Wada, N., Watanuki, K., Narita, K., Suzuki, S., Kudo,
G. and Kume, A. 2005. Climate change and shoot elongation of alpine dwarf pine (Pinus pumila Regel): comparisons between six Japanese mountains. Phyton, 45: 253-260.

Yamaguti, N., Tipton, V. J., Keegan, H. L. and Toshioka, S. 1971. Ticks of Japan, Korea and the Ryukyu Islands. Brigham Young Univ. Sci. Bull. Biol. Ser., 15: 1-226. 